\title{
Vibration effect influence upon non-aqueous phase liquid migration in double-porosity soil
}

\author{
Norhan Abd Rahman 1 , Loke Kok Foong ${ }^{2}$, Ramli Nazir ${ }^{1}$ and Roland W Lewis ${ }^{3}$ \\ ${ }^{1}$ Universiti Teknologi Malaysia, Faculty of Civil Engineering, Centre of Tropical Geoengineering, Johor, Malaysia (norhan@utm.my) \\ 2 Universiti Teknologi Malaysia, Faculty of Civil Engineering, Johor, Malaysia \\ ${ }^{3}$ University of Wales Swansea, School of Engineering, Swansea, W. Glam, SA2 8PP, United Kingdom
}

doi: $10.4154 / g c .2018 .14$

Article history:

Manuscript received January 06, 2018 Revised manuscript accepted June 10, 2018 Available online October 12, 2018

Keywords: vibration, laboratory experiment, NAPLs migration, aggregate kaolin, image analysis method

\begin{abstract}
Natural disasters such as earthquakes, El-Nino, tsunamis and water pollution have a negative impact on human health and living environment. Some of these may give rise to subsurface vibrations that can potentially increase groundwater pollution risks in double-porosity systems. The more complicated situation was where underground storage tanks and petroleum pipeline damage have caused the leakage of non-aqueous phase liquids (NAPLs) which migrated into the groundwater resources. These problems need to be addressed by both professionals and researchers worldwide to ensure the sustainability of groundwater utilization. This paper aims to investigate and understand NAPL migration in vibrated double-porosity soils. To do so it was necessary to study the phenomena and characteristic of soil structure and the pattern of NAPL migration to identify cost-effective remediation schemes. A laboratory experiment was conducted to study the phenomena and characteristics of vibration response and NAPL migration in double-porosity soil deformation under vibration effect using a digital image processing technique (DIPT). The outcomes of the experiment show that the gradual increase of vibration table excitation frequency yielded different vibration responses from the respective soils. This indicated that soil surface acceleration depended significantly on the soil conditions, soil water content, soil structure and the pattern of soil fracturing. NAPL migration was faster in sample 2 with $150 \mathrm{ml}$ toluene than sample 1 with $70 \mathrm{ml}$ toluene and this could be because the greater amount of toluene in sample 2 exerted an extra entry force on top of the soil sample that had yet to migrate through the sample surface. Finally, it was concluded that the DIPT may provide detailed information, and can be used to understand and identify the remediation method as well as to ensure the sustainable consumption of groundwater.
\end{abstract}

\section{INTRODUCTION}

Both development and industrial activities have been proven to have a negative impact on and exacerbate natural disasters, climate change, environmental pollution, and therefore affect human health. Subsurface contamination by petroleum hydrocarbons through underground storage tank leakage and spillage is one of the most challenging geo-environmental issues faced by many countries and results in the reduced quality of groundwater. More complex problems emerge when the surface or subsurface has experienced earthquake vibration, which could promote the migration of petroleum hydrocarbons into groundwater resources. Petroleum hydrocarbons, also known as non-aqueous phase liquids (NAPLs), are organic solvents such as toluene, benzene, hexane and naphthalene that usually arise from industrial activities, that do not mix with water (TIAN et al., 2014). NAPL may be divided into two categories, dense non-aqueous phase liquids (DNAPL), which are more dense than water, and light non-aqueous phase liquids (LNAPL), which are less dense than water. The LNAPL migrate through the unsaturated soil and float on the groundwater surface, while the DNAPL may penetrate into the underlying groundwater. Fuels released such as gasoline, diesel, lubricants, jet fuel, collectively referred to as LNAPLs, are of concern due to the hazards caused to human-health and the environment when in contact with LNAPLs (TOMLINSON et al., 2017). Earthquake vibration causing cracked soil, deformation of soil structure, and unstable soil structure may exacerbate
NAPL pollution (LOKE et al., 2017). According to TOMLINSON et al. (2017), liquid migration, in reference to LNAPL behaviour and movement in the subsurface, is complicated. The speed and phenomena of the petroleum hydrocarbon liquid migration into the subsurface system may be more intricate under the influence of vibrated porous soil. Therefore, a better understanding of NAPL migration in vibrated porous soil was necessary in order to study the phenomena and characteristics of soil structure. The pattern of NAPL migration is important to identify remediation schemes and to ensure the sustainability of groundwater resources and the geo-environment. Porous media such as deformable double-porosity soil has been classified as soils with interaggregate pores and intra-aggregate pores that display a bimodal pore-size distribution pattern and are normally found in agricultural topsoils and compacted soils (LI \& ZHANG, 2009; ELZEIN et al., 2006). A more comprehensive understanding with respect to NAPL migration under the phenomena of fractured double-porosity soil is still required. This study proposed a new model concept with soil porosity that includes features from the three continuums of fracture porosity, primary porosity, and secondary porosity (based on a literature review). The fracture porosity continuum developed through the affect of vibration had caused the double-porosity soils to fracture. Meanwhile, the primary porosity and secondary porosity continuums concept represents double porosity soils that consist of inter-aggregate and intra-aggregate pore matrix blocks, respectively, with different hydraulic properties embedded in a network of interconnected 
fractures (LOKE et al., 2017). The most critical contaminants include petroleum hydrocarbons such as toluene, (LNAPL), which have been selected as the liquids used in this study.

The soil structure affects the flow rate and characteristics of liquid migration. In common conditions, soil that displays two specific scales of porosity media is termed a double-porosity soil (CARMINATI et al., 2008). Geo-materials habitually display two scales of porosity, which are macro pores and micro pores (MANRIQUE et al., 2007). According to SA'ARI et al. (2015), doubleporosity soils have different hydraulic properties of two sub-region media due to the differing pore size characteristics. Similarly, BARBARA et al. (2016) \& FREDLUND et al. (2010) found that fractured porous media significantly change the mechanical properties and hydrological characteristics. Existing research recognizes the critical role played by cracked soil where it can significantly influence the water flow through the fractured soil structure (KRISNANTO et al., 2014). According to LAKELAND et al. (2014), fractured double-porosity soil is formed due to earthquakes or other vibration effect in which loosely packed water-saturated granular soils (sand and silt) are subjected to great shaking, where they may liquefy and cause large deformation of the soil structure with strong destructive power. In earthquake engineering theory, the bedrock motion with the highest response is the Peak Ground Acceleration (PGA) and the free surface motion with highest response is the Peak Surface Acceleration (PSA). These accelerations can be either amplify or disamplify, based on Eurocode 8 (2004) part 1 for classifying five ground types (A to E), where it helps to characterizing the soil type (LOKE et al., 2016). Therefore, this study used ground response analysis to identify the soil sample by the propagation of ground motion to the surface because in practice, ground response analysis was used to determine the crack and ground type.

LEWANDOWSKA et al. (2005) stated that soil in the laboratory can be used to create double-porosity for one-dimensional infiltration experiments, which is how most studies concerning double-porosity soil are carried out. Furthermore, laboratory prepared double-porosity kaolin soil was used for one-dimensional drying and consolidation experiments as performed by BAGHERIEH et al. (2009). Double-porosity media have been studied in the past few decades by a number of researchers. For example, (ALAZAIZA et al., 2017; NGIEN et al., 2016; SA'ARI et al., 2015; TRANNGOC et al., 2014; RYZHIK, 2007; PAO \& LEWIS, 2002) used numerical methods and experimental methods on doubleporosity soil media and have thereby contributed to an understanding of the soil characteristics. However, the studies were limited to intact double-porosity soils without applying any vibration effect on these soils.

In this research, a digital image analysis method was used to study the migration of LNAPL in a fractured double-porosity soil represented by an S300 kaolin soil. A digital image analysis method was used to understand and analyse the pattern of LNAPL migration in a fractured double-porosity soil. An overview by AGAOGLU et al. (2015) found that the laboratory work involved non-destructive and non-intrusive imaging techniques which used characterization and observation of multiphase flow system for greater accuracy. Therefore, a number of researchers (JANINA et al., 2017; SITTHIPHAT \& SIAM et al., 2016; PENG et al., 2015; SA'ARI et al, 2015; KAMARUDDIN et al., 2011; NGEIN et al., 2011; FLORES et al., 2011; OOSTROM et al., 2007) have carried out various techniques and methods of non-destructive image analysis for liquid migration experiments. As stated by MAAS \& HAMPEL (2006), an image analysis technique in the field of civil engineering was normally used to study the object flow absorption movement in boundary layers and liquid migration of small properties specific to the propagation of structure crack extension, and for this argument, a digital image processing technique was acceptable for use in the study of LNAPL migration in a fractured double-porosity soil.

In addition, NGIEN et al. (2012) asserted that the problems inherent in gathering data concerning hydrocarbon liquid movement characteristics and the laboratory experiments will go a long way in the effort to comprehensively understand, monitor, observe and solve groundwater contaminant problems. To the best of our knowledge and upon reviewing other research papers, experiments on LNAPL migration in fractured double-porosity soil under vibration effect represent a knowledge gap to be investigated and evaluated. Therefore, a laboratory experiment was conducted to study the phenomena and characteristics of LNAPL migration in double-porosity soil deformation under vibration effects. Thus, to achieve the purpose of this study, the identified objectives were (i) to investigate the vibration responses with different vibration frequency for the double-porosity soil, (ii) to determine the characteristics of LNAPL migration in vibrated double-porosity using image analysis, (iii) to distinguish processes controlling LNAPL migration with different quantities of Toluene in fractured double-porosity soil.

\section{MATERIALS AND METHODS}

The laboratory soil sample preparation, laboratory experiment and image processing setup used in this study are outlined below.

\subsection{Laboratory soil sample preparation}

The soil sample material utilized for this study to create doubleporosity was commercially available kaolin soil produced by Kaolin Malaysia Sdn Bhd. The kaolin soil properties were tested based on British Standard BS 1377-2:1990 and BS 1377-5:1990 to obtain liquid limit $=41.5 \%$, plastic limit $=27.5 \%$, plasticity index $=14 \%$, particle density $=2.66 \mathrm{Mg} / \mathrm{m}^{3}$, particle size distribution $=(4 \%$ sand; $91 \%$ silt; $5 \%$ clay $)$ and falling head permeability test $\left(\mathrm{K}_{\text {average }}\right)=5.41 \times 10^{-9} \mathrm{~m} / \mathrm{s}$. The kaolin soil was classified under the Unified Soil Classification System as silt with low plasticity (ML) based on the value of Atterberg limits and particle size distribution. Based on HILLEL (1998), the total porosity for a double-porosity soil is defined as the sum of the inter-aggregate and intra-aggregate porosities. This is given by Eq. (1) as

$$
\varphi_{t}=\varphi_{\text {int } e r}+\varphi_{\text {int } r a}
$$

where $\varphi_{t}$ is the total porosity, $\varphi_{\text {int } e r}$ is the inter-aggregate porosity, and $\varphi_{\text {int ra }}$ is the intra-aggregate porosity. The approach used in this study for estimating the inter-aggregate porosity and intraaggregate porosity of the aggregated soil is to adopt the intraaggregate porosity as the volumetric moisture content at field capacity (DAVID \& TRUMBORE, 1995). The SOIL SCIENCE SOCIETY OF AMERICA (1987) has identified the field capacity as the moisture content remaining in a soil for two or three days after wetting with water, which becomes negligible after free drainage. In this experiment, it was further observed that no free drainage of the cured soil occurred after curing for the field capacity. Therefore, this theory brings us to Eq. (2).

$$
\varphi_{\text {int } e r}=\varphi_{t}-\varphi_{w}
$$

where $\varphi_{w}$ is the volumetric water content. The total porosity and volumetric water content can be calculated in turn using Eqs. (3) to (4), respectively (GHEZZEHEI \& OR, 2003).

$$
\varphi_{t}=\frac{V_{v}}{V_{t}}=\frac{V_{t}-V_{s}}{V_{t}}
$$




$$
\varphi_{w}=\frac{V_{w}}{V_{t}}
$$

where $V_{v}$ is the volume of voids, $V_{t}$ is the overall volume of the sample, $V_{s}$ is the volume of solids only, and $V_{w}$ is the volume of water. The overall volume of the sample is the volume after compression and can be calculated through Eq. (5). (GHEZZEHEI AND OR 2003)

$$
V_{t}=H \frac{\pi}{4} d^{2}
$$

where $H$ is the soil sample height, and $d$ is the soil sample diameter. The volume of solids can be calculated using Eq. (6). (GHEZZEHEI AND OR 2003)

$$
V_{s}=\frac{M_{s}}{\rho_{s}}
$$

where $M_{s}$ the mass of solids is equal to $M_{t}$ divided by $(1+$ water content), $M_{t}$ is the total mass and $\rho_{s}$ is the particle density. The volume of water can be calculated by dividing the mass of water by the density of water as in Eq. (7). (GHEZZEHEI AND OR 2003).

$$
V_{w}=\frac{M_{w}}{\rho_{w}}
$$

Therefore, the double-porosity value for this study can be calculated by using Eqs. (1) to (7) with the parameter values such as $H=0.1 \mathrm{~m}, d=0.094 \mathrm{~m}, \rho_{s}=2.66 \mathrm{Mg} / \mathrm{m}^{3}, M_{t}($ sample 1$)=$ $1.012 \mathrm{~kg}$, moisture content sample $=30 \%$. By using these values as mentioned, the inter-aggregate porosity and intra-aggregate porosity for sample was calculated as 0.24 and 0.34 , respectively. It is evident that the $30 \%$ moisture content used in this study falls within the range established from the available literature, as the moisture content at field capacity ranged from 0.226 to 0.40 (FOOD AND AGRICULTURE ORGANIZATION 2005; INTERNATIONAL ATOMIC ENERGY AGENCY 2008). Thus, the total porosity was $0.24+0.34=0.58$.

The method used to prepare the aggregated kaolin soil sample has been based on the established method by BAGHERIEH et al. (2009). The preparation of the kaolin soil sample used 30\% water content, which was based on the value of the liquid limit, and optimum moisture content for kaolin soil was $28 \%$. Thus, the dried kaolin powder was mixed with $30 \%$ water content and constant pouring of distilled water was applied to control the water content within the mixture. The mixture was kept in cool conditions for a minimum of 24 hours to equalise the mixture which

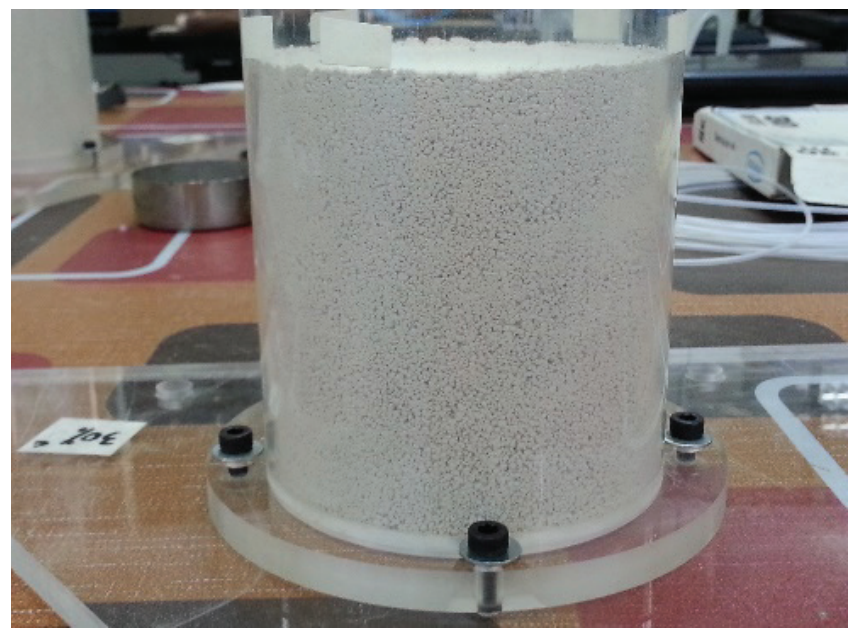

Figure 1. The prepared kaolin soil was placed in a plastic bag for the purpose of maintaining the soil moisture content. Then the mixture was broken by hand and passed through a $2.36 \mathrm{~mm}$ sieve to obtain kaolin granules to create the double-porosity soil structure. A pre-determined amount of kaolin granules with a weight of $0.93 \mathrm{Kgwas}$ placed in a circular acrylic soil column and compressed to a height of $100 \mathrm{~mm}$ using a compression machine at a compression rate of $1 \mathrm{kgf} / \mathrm{cm}^{2}$. The $100 \mathrm{~mm}$ height of soil sample was chosen to ensure uniformity throughout the sample depth. The prepared aggregated soil sample is shown in (Fig. 1).

The circular acrylic soil column with a sealed base with dimensions of $300 \mathrm{~mm}$ high x $100 \mathrm{~mm}$-outer diameter and $94 \mathrm{~mm}$ inner diameter was used throughout the experiment. The circular acrylic soil column was specially designed to be used on a vibration table and for the observation of the phenomena occurring throughout the whole acrylic soil column. The acrylic soil column with a triangular base plate was securely fixed and bolted on the vibration table in order to prevent any movement and bouncing of the soil column during the vibration process.

The experimental setup and the acrylic circular soil column showed similar effects when using either an economical vibration table, or a shake table. To ensure that the vibration table functioned well and could produce the same reliable data as the shake table, the vibration table frequencies must be calibrated using a high sensitivity accelerometer together with a Dewesoft Sirius System data-logger to check and obtain the excitation frequency for the vibration table. The vibration table with a built in frequency control panel was vibrated in the vertical direction. BARRY et al. (2008) reported that major earthquakes have an upper frequency of $20 \mathrm{~Hz}$. However, this can be much lower depending on the seismic activity. A moderate to low seismic earthquake such as the one that struck Ranau, Malaysia is one such example. This 6.0 magnitude earthquake had a peak ground acceleration of $0.12 \mathrm{~g}$ (HARITH et al., 2017). Thus, based on the details, seismic activity and SeismoSignal software analysis display an approximate vibration frequency of only $0.95 \mathrm{~Hz}$. Following this, vibration frequency in the range of $0.29 \mathrm{~Hz}$ to $0.98 \mathrm{~Hz}$ was adopted in this study. The coupling system between the accelerometer and soil used soft plasticine with a strong bonding characteristic. Meanwhile, another accelerometer was attached to the vibration table near to the soil sample with the same procedure. The vibration table setup used to vibrate the aggregated soil sample was developed by LOKE et al. (2017) as shown in (Fig. 2).

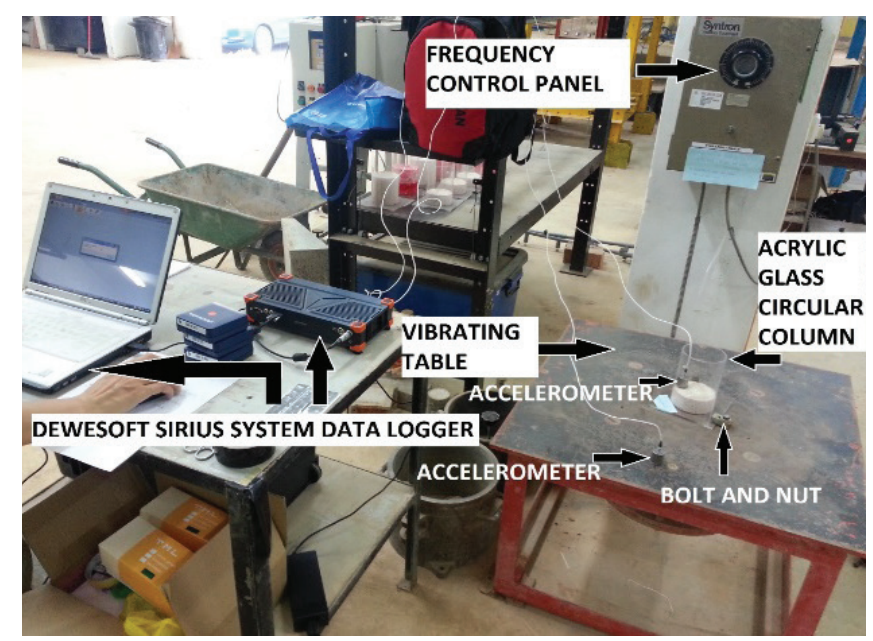

Figure 2. 3D diagram of vibration table setup (LOKE et al., 2017) 

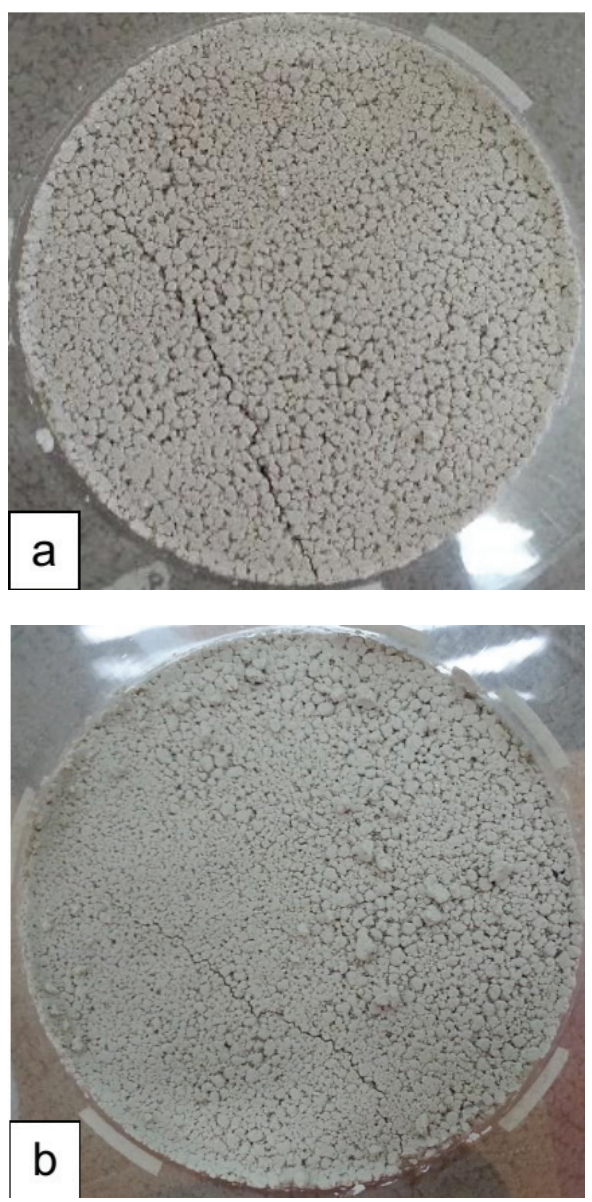

Figure 3. a) Sample 1 after vibration process with fracture. b) Sample 2 after vibration process with fracture.

The result of the fractured soil pattern with $30 \%$ moisture content for samples 1 and 2 after the vibration process are shown in (Fig. 3). The theory of fractured double-porosity was to prove that the vibration effect had caused the double-porosity soil to fracture. The fracturing on the top of soil can be clearly seen.

\subsection{Laboratory experiment and image processing setup procedure}

The circular acrylic soil column containing fractured doubleporosity soil was used to observe and monitor the LNAPL migration that occurs inside the whole circular column area with the aim of simulating groundwater contamination and non-intrusion of the original soil sample setup. In each sample, the experimental measurement and setup of the $\mathrm{V}$ shape mirror and soil column position was arranged as shown in (Fig. 4) for LNAPL migration image acquisition.

A Nikon D90 DSLR digital camera was used for LNAPL migration image acquisition at specific time intervals. The camera comes equipped with a sensor size of $23.6 \mathrm{~mm} \times 15.8 \mathrm{~mm}$ and used a medium size image format of 3216 x 2136 pixels resulting in each pixel having a size resolution of $5.6 \mu \mathrm{m} \times 5.6 \mu \mathrm{m}$. During the process of image capture, a remote control was used to prevent movement and shaking of the camera. To soften the problem of insufficient image acquisition, this experiment used a single digital camera, and two mirrors for reflection positioned behind the circular soil column were adjusted to enable a clear image facing the digital camera. In addition, on the spot images of the LNAPL migration throughout the whole area of the soil column circum-

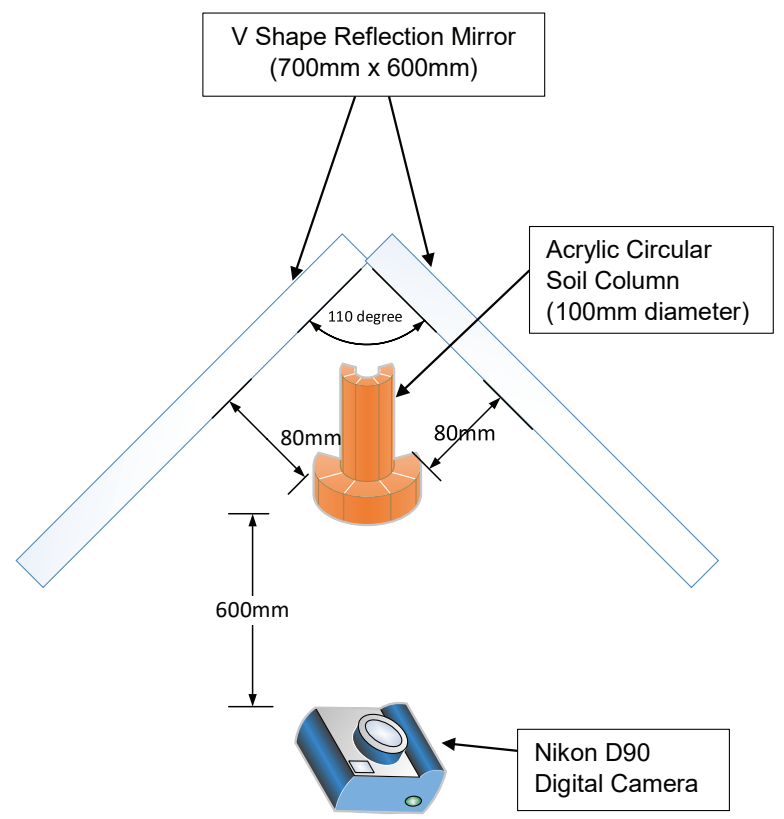

Figure 4. Digital image acquisition experiment setup and measurement position

ference can be captured by just a single click of the digital camera. The experiment light source came from a light output of 2600 lumens/watt that was secured above the soil column. A white paper with pre-drawn gridline $(20 \mathrm{~mm} \times 20 \mathrm{~mm})$ was first sheathed onto the soil column and used as a control point on the reference image. The experiment started by instantaneously pouring the LNAPL into the top centre of the fractured soil sample in the circular acrylic soil column. Sample 1 used $70 \mathrm{ml}$ of toluene, while $150 \mathrm{ml}$ of toluene was used in soil sample 2 . The toluene for both experiments was dyed red using Oil-Red-O powder to enhance the visibility during the migration process. After the toluene had covered the whole surface area of the fractured soil sample, the first digital image of toluene migration was captured. In both experiments, subsequent digital images were taken at specific time intervals to capture the LNAPL migration. A total of 76 images were subsequently recorded over 5 minutes for soil sample 1 , while 19 images were captured in 57 seconds for soil sample 2 .

The digital images captured for both experiments were saved in JPEG format as shown in (Fig. 5) and transferred to computer for image processing analysis using Matlab and Surfer Software. The Matlab routines were used to perform the following task; to extract an area of interest from the captured image and to transform the area of interest from the distorted image to a scale image via the affine transformation method; to convert the JPEG scale images to Red Green Blue (RGB) and Hue Saturation Intensity (HSI) images; to extract HSI digital value from HSI image and save the HSI value in a text file format. Then, Surfer software was used to digitize the control point from the reference image and to generate a map or plot the migration pattern of LNAPL in porous media using the HSI value. A reference image was digitized with the area of interest, which refers to a pre-determined migration boundary area (front image and $\mathrm{V}$ shape reflection image) for the experiment that contained the LNAPL. Finally, the contour plot pattern was plotted for the LNAPL migration in fractured porous media based on the generated HSI value from image processing analysis. The HSI contour plot of LNAPL migration behaviour can provide detailed information to facilitate researchers to understand the pattern of LNAPL migration characteristic and the migration flow. 


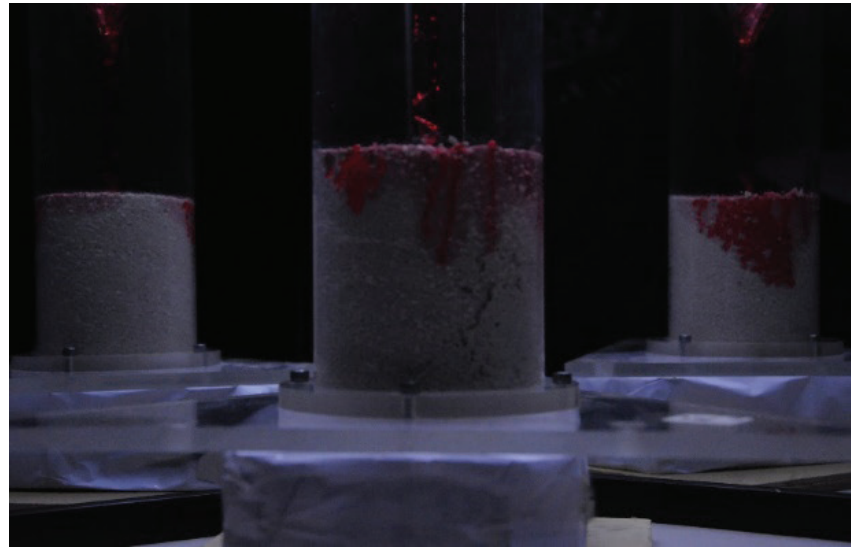

Figure 5. Digital image in JPEG format

\section{RESULTS}

The results of the surface acceleration and vibration table acceleration for samples 1 and 2 with $30 \%$ moisture content are shown in (Fig. 6). Each frequency range has a different response, however only the peak acceleration has been chosen for discussion. Referring to (Fig. 6), the acceleration response result shows the highest peak soil surface acceleration value at $1.52 \mathrm{~g}$ and the lowest peak soil surface acceleration value at $0.44 \mathrm{~g}$, with the highest soil surface acceleration response observed to be at the middle of the vibration table excitation frequency range.

The pattern and relationship could be seen to increase in relation to table acceleration. Therefore, it has been observed that

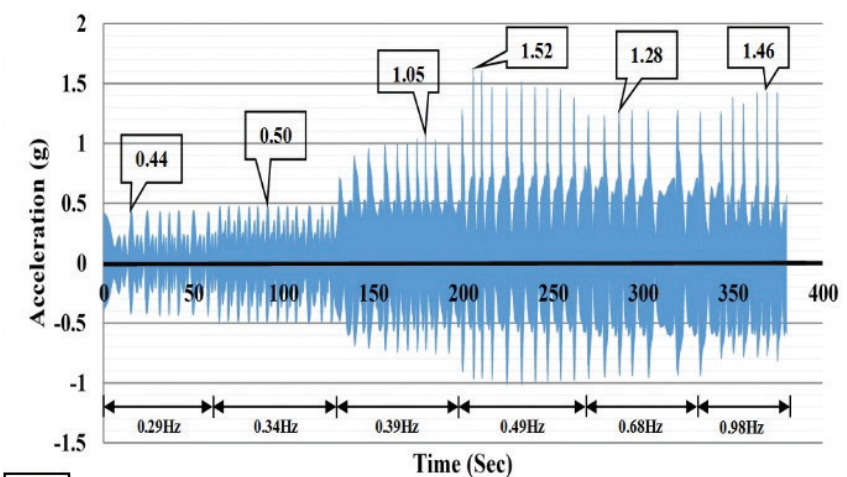

a

Figure 6. a) Surface acceleration response b) Vibration table acceleration response for sample 1 and 2 with $30 \%$ moisture content.
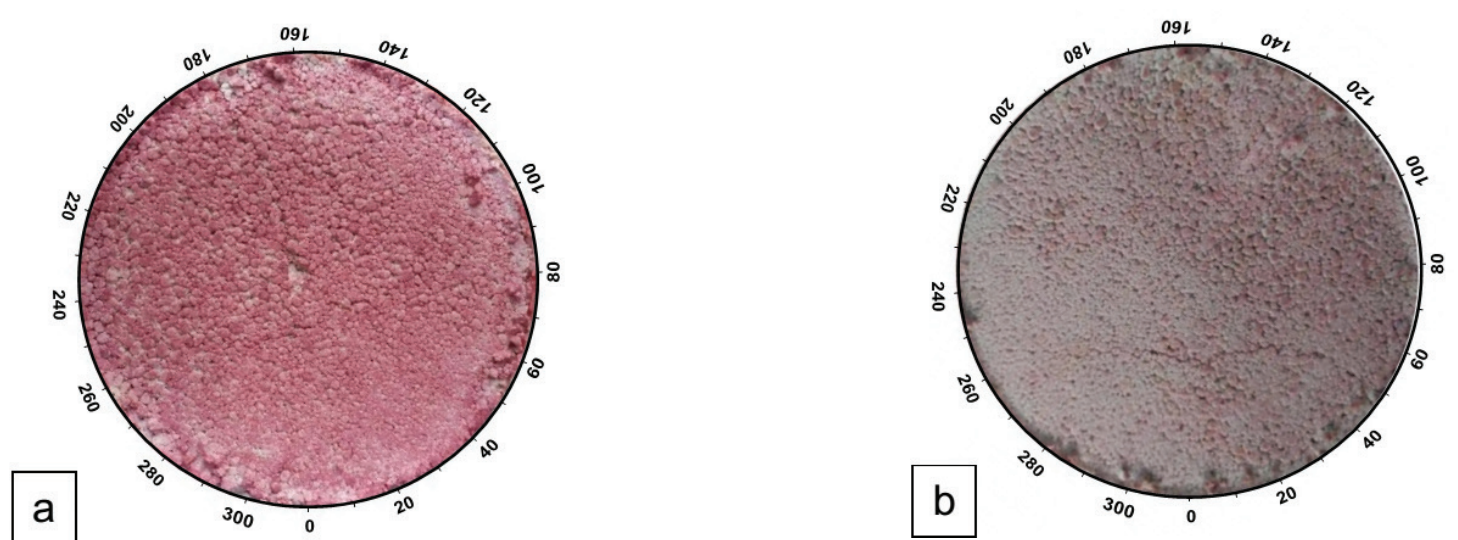

Figure 7. a) Sample 1 (70 ml LNAPL). b) Sample 2 (150 ml LNAPL) migrated soil surface with measurement of actual column circumference zone. the gradual increase of vibration table excitation frequency yielded different responses from the respective soils. Furthermore, during the observations of samples 1 and 2, the aggregated kaolin soil started to fracture at a frequency of $0.39 \mathrm{~Hz}$ and when the peak surface acceleration was about $0.91 \mathrm{~g}$. The fractured soil sample displayed dis-amplification shaking because the soil was still in the stiff condition. Therefore, based on Eurocode 8 (2004) part 1 for classification of ground type, samples 1 and 2 have ground type B, which has a very stiff soil, because soil samples 1 and 2 with $30 \%$ moisture content have dis-amplification shaking during the vibration process.

The results of the LNAPL migration process for the top soil surface with the divided measurement of actual size column circumference zone for samples 1 and 2 are shown in (Fig. 7). The downward migration pattern of the HSI contour plot of dyed LNAPL with $70 \mathrm{ml}$ and $150 \mathrm{ml}$ in the fractured double-porosity soil sample with $30 \%$ moisture content for samples 1 and 2, respectively, are shown in (Fig. 8). In both samples, given the method of introduction of the solution to the soil surface, the flow of the LNAPL would have migrated into the kaolin soil sample before the whole soil sample surface was covered. The test samples exhibited a distinctive aggregation of kaolin granules after the vibration effect and the width of the fractured soil surface in the vibrated sample was measured by using a crack width microscope model 58-C0218. The results of the fractured soil surface for samples 1 and 2 were $0.8 \mathrm{~mm}$ and $1.3 \mathrm{~mm}$, respectively.

In sample 1, the selected HSI plots of dyed LNAPL migration at intervals of 5, 120, 240, and 300 seconds, respectively, are shown in (Fig. 8a). According to the HSI intensity contour plot

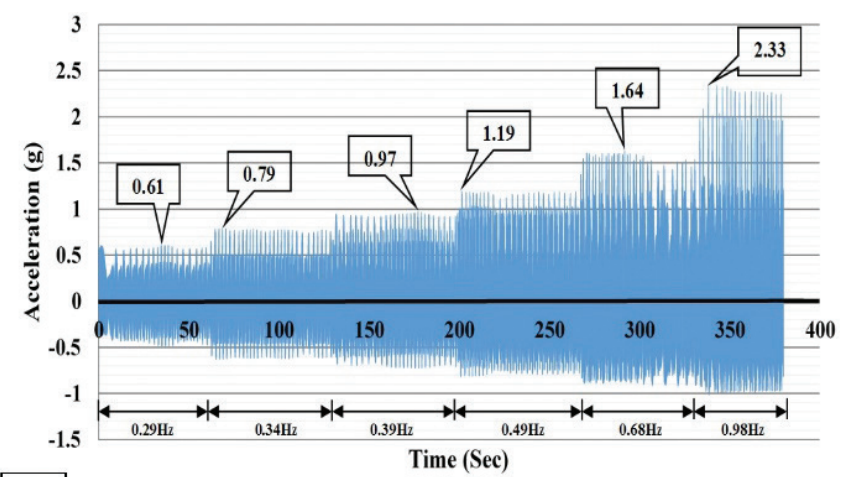

b

\section{竞}




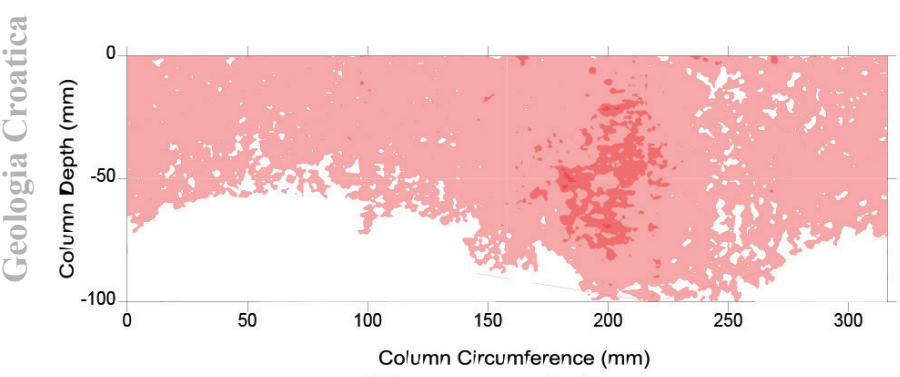

(5 seconds)

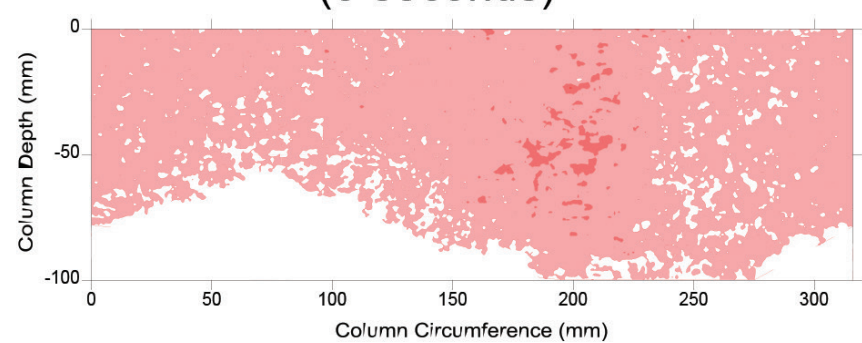

(120 seconds)

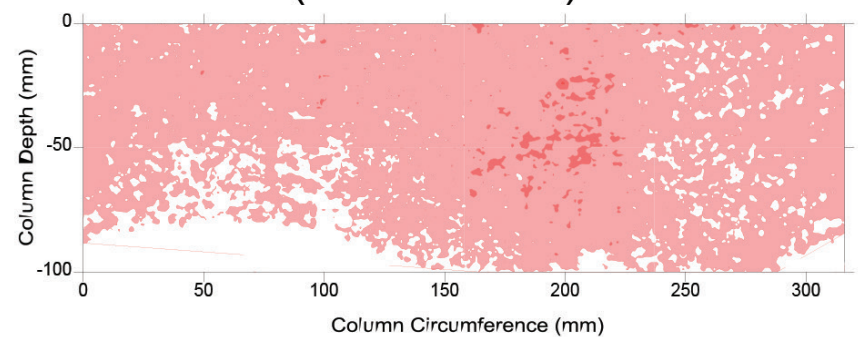

(240 seconds)

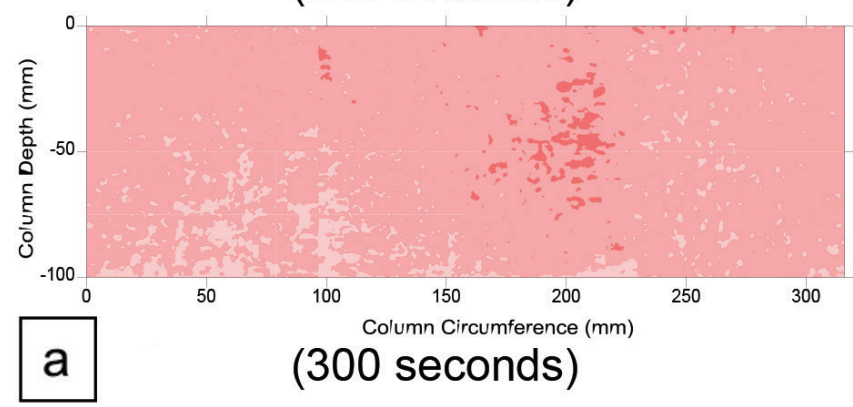

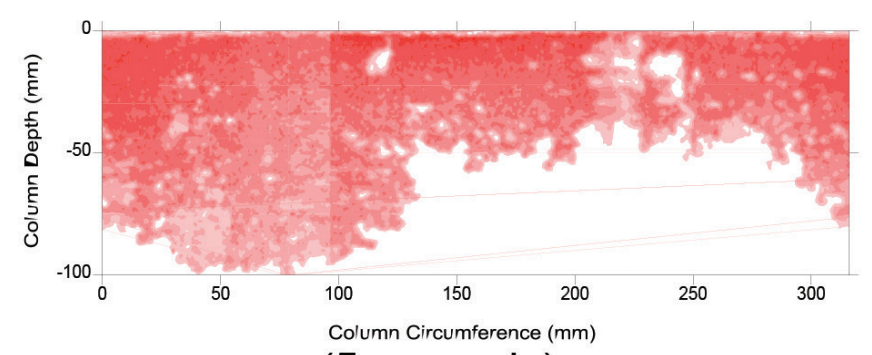

(5 seconds)

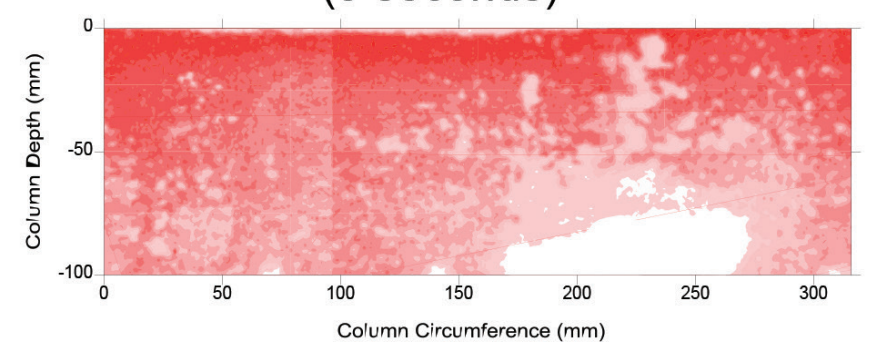

(24 seconds)

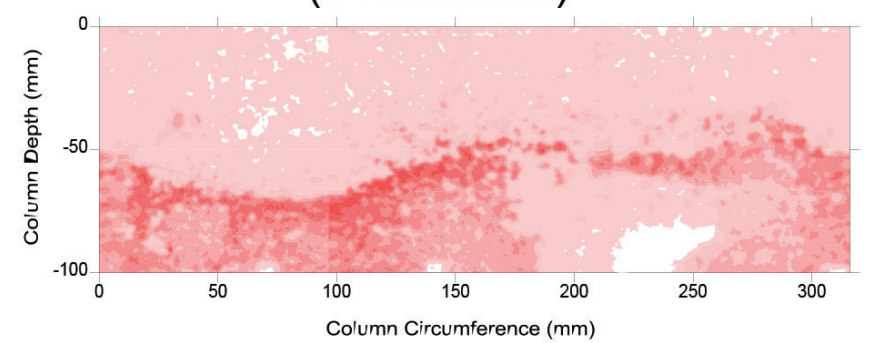

(36 seconds)

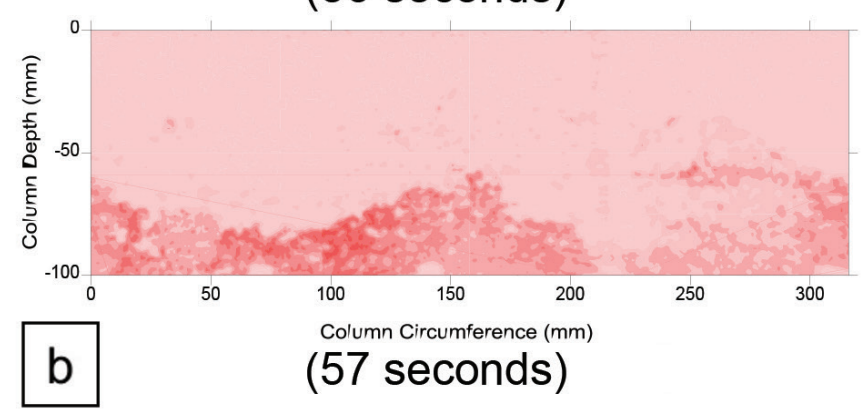

Figure 8. a) Sample 1 (70mI LNAPL). b) Sample 2 (150mI LNAPL) HSI plots of downward migration in fracture double-porosity soil

result, the flow of the dyed toluene migration was not consistently downward toward the front $\mathrm{x}$-axis horizontal line as the fractured double-porosity soil was non-homogenous. Rapid migration occurred at the cracked soil surface compared to uncracked areas of the soil surface as shown in (Fig. 7a). For the dyed LNAPL to completely recede from view over the whole soil surface area of the test took about 4 seconds, which is very rapid. Meanwhile, the overall duration for dyed LNAPL migration from the top surface to the bottom was 300 seconds and further observation at 600 seconds showed no changes in migration pattern where the LNAPL migration reached $100 \%$ downward depth of the soil column. At 5 seconds after the commencement of the experiment, the dyed LNAPL migration reached three quarters of the test sample depth at the location of the fractured soil surface (Fig. 8a).The LNAPL ( $70 \mathrm{ml})$ could migrate to the bottom in 300 seconds. This is because the capillary force that was exerted by a small quantity of the LNAPL was not sufficient enough to help migration rate.

In sample 2, the intervals of 5, 24, 36 and 57 seconds, respectively, were selected for dyed LNAPL migration HSI contour plot
(Fig. 8b). The LNAPL migration was similar to the results found in sample 1. The flow of dyed LNAPL migration was not uniformly downward at the front boundary horizontal line due to the inhomogeneity of the fractured double-porosity soil structure. At 5 seconds after the initiation of the experiment, the dyed LNAPL migration reached three quarters (3/4) of the test sample at the location of fractured soil surface (Fig. 7b). It took about $24 \mathrm{sec}-$ onds for the dyed LNAPL to completely disappear from the top soil surface area into the fractured soil sample of the test. Meanwhile, the overall duration for the dyed LNAPL migration from the top surface to the bottom was 57 seconds and further observation at 300 seconds showed no changes in migration pattern where the LNAPL migration fully reached $100 \%$ depth of the soil column.

From the results, it can be seen that soil sample 2 had the faster migration as a shorter time was taken for the LNAPL to reach the bottom of the soil column. Soil sample 2, with the fractured width of $1.3 \mathrm{~mm}$, had a greater entry pressure compared to sample 1 with a $0.8 \mathrm{~mm}$ wide fracture because the fracture width 


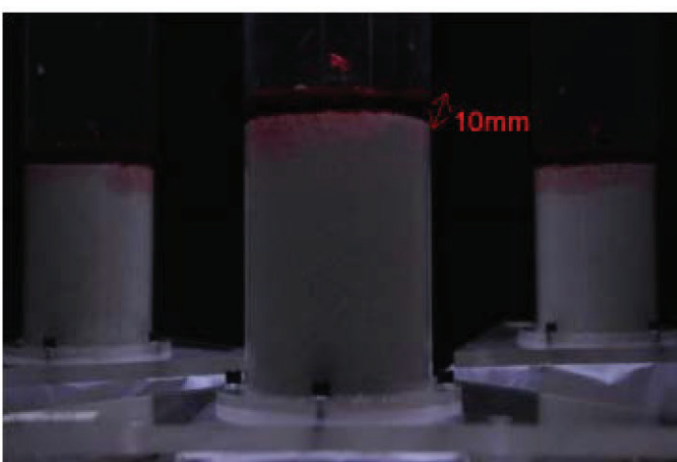

a) Sample 1 LNAPL thickness with $10 \mathrm{~mm}$

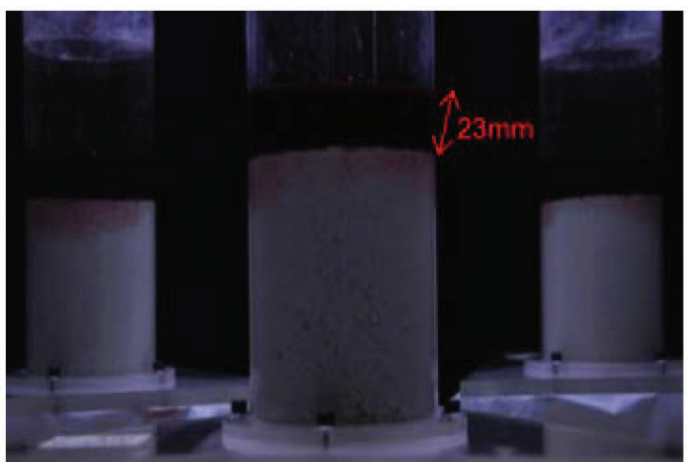

b) Sample 2 LNAPL thickness with $23 \mathrm{~mm}$

Figure 9. The LNAPL thickness for sample 1 and 2

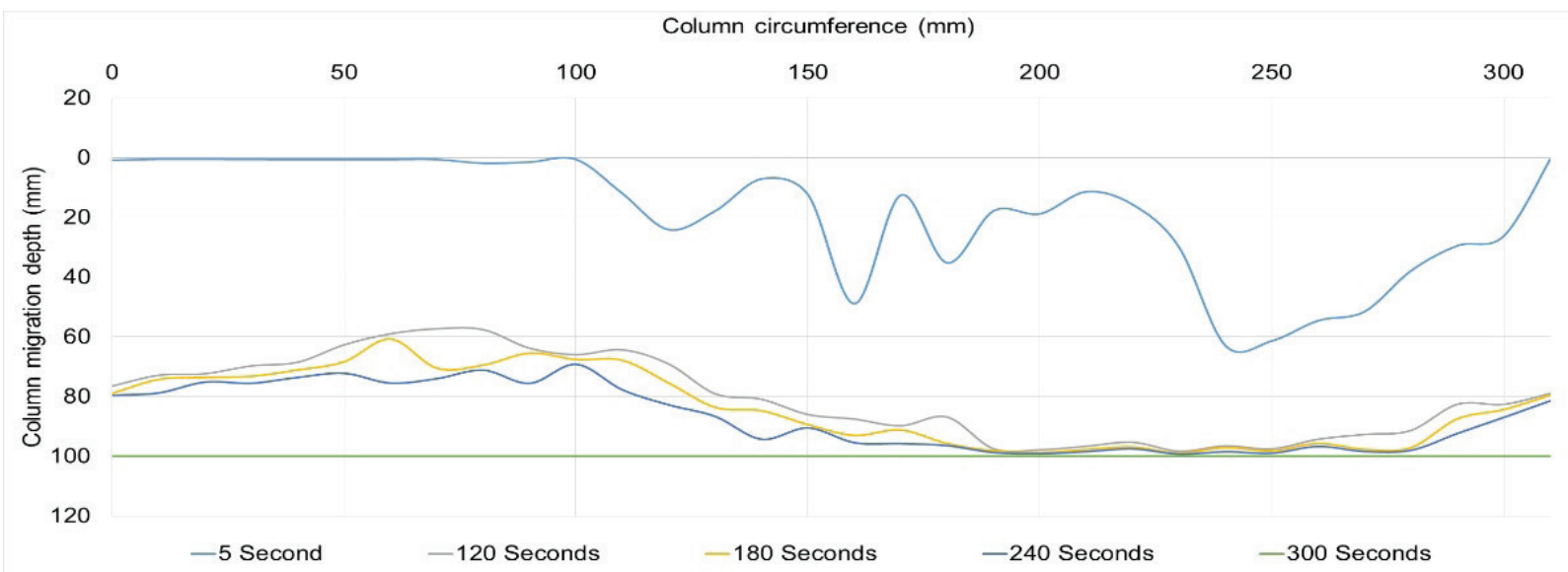

Figure 10. Measured values of LNAPL migration depth as a function of column circumference for selected critical time interval in sample 1.

controlled the entry for the liquid migration into the fractured double-porosity soil. The driving force with which a LNAPL release could migrate into the unsaturated fractured double-porosity soil is determined principally by the LNAPL thickness (the height of the LNAPL release above the soil surface) because the LNAPL release was initially greater. However, the LNAPL thickness could reduce and dissipate with time finally leading to the migration of LNAPL into the fractured double-porosity soil. The LNAPL thickness for samples 1 and 2 are shown in (Fig. 9) and are $10 \mathrm{~mm}$ and $23 \mathrm{~mm}$, respectively. Dissipation times of the liquids were 4 seconds and 24 seconds, respectively for the two samples for total migration from the soil surface into the soil. Of the two samples, sample 1 migrated faster compared to sample 2 due to greater entry pressure. Sample 2 entry pressure was lower due to greater LNAPL thickness and the larger quantity of the LNAPL.

Furthermore, migration behaviour and migration rate differed between samples 1 and 2 with a shorter migration time for sample 2 because of the capillary force exerted by the dyed LNAPL pressure in the top surface of the soil sample that had yet to migrate into the soil sample. This is seen by the darker saturation colour in the 5 second HSI plot in sample 2 compared to sample 1 . In addition, air bubbles were continuously observed at the soil surface of LNAPL to be reducing due to the wettability of

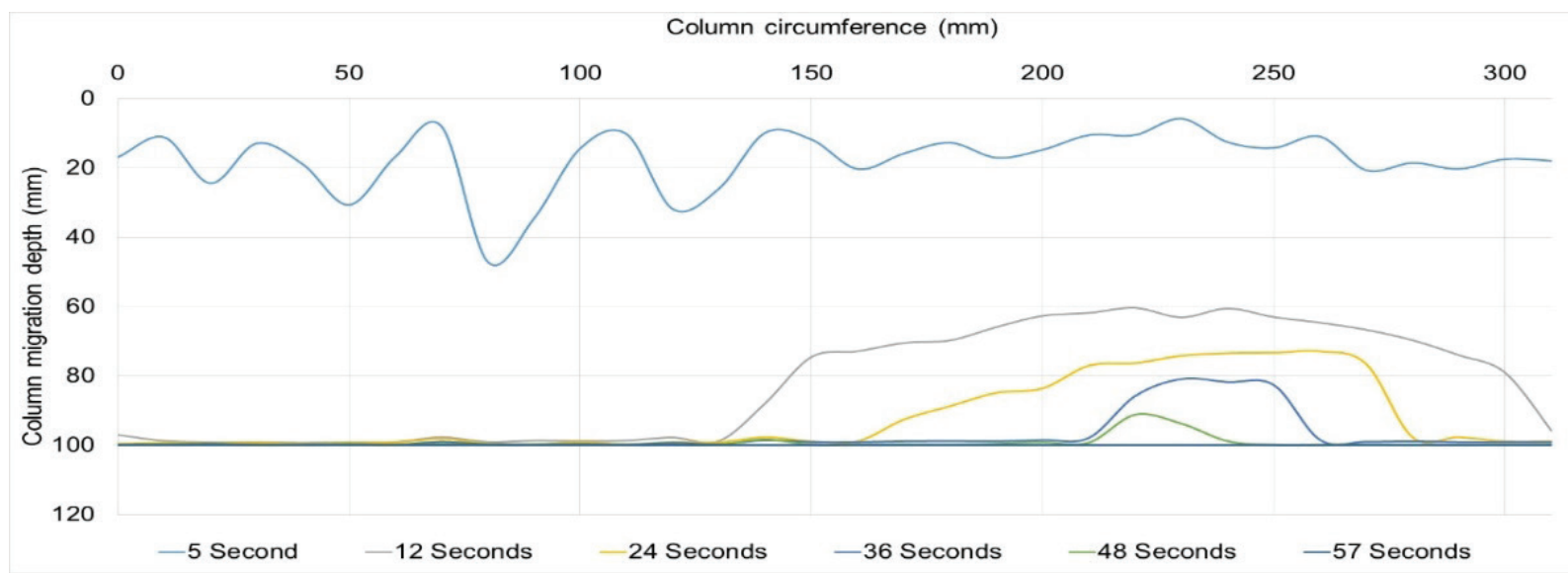

Figure 11. Measured values of LNAPL migration depth as a function of column circumference for selected critical time interval in sample 2. 
Table 1. Migration flow rate for every $50 \mathrm{~mm}$ column circumference.

\begin{tabular}{|c|c|c|c|c|}
\hline \multirow{3}{*}{$\begin{array}{l}\text { Column Circumference } \\
\text { Zone }(\mathrm{mm})\end{array}$} & \multicolumn{4}{|c|}{ Migration Flow Rate $(\mathrm{mm} / \mathrm{s})$} \\
\hline & \multicolumn{2}{|c|}{ Soil sample 1 (70ml LNAPL) } & \multicolumn{2}{|c|}{ Soil sample 2 (150ml LNAPL) } \\
\hline & $\begin{array}{l}\text { Higher Flow Between Initial } \\
\text { to } 5 \text { Seconds }\end{array}$ & $\begin{array}{l}\text { Average Flow for All the Time } \\
\text { Interval }\end{array}$ & $\begin{array}{l}\text { Higher Flow Between Initial } \\
\text { to } 5 \text { seconds }\end{array}$ & $\begin{array}{l}\text { Average Flow for All the Time } \\
\text { Interval }\end{array}$ \\
\hline 0 & 0.837 & 2.833 & 16.917 & 4.669 \\
\hline 50 & 0.598 & 2.522 & 76.778 & 12.927 \\
\hline 100 & 0.597 & 2.703 & 20.551 & 5.343 \\
\hline 150 & 12.397 & 4.579 & 11.834 & 3.656 \\
\hline 200 & 18.837 & 5.586 & 14.797 & 3.894 \\
\hline 250 & 61.403 & 9.145 & 14.238 & 3.814 \\
\hline 300 & 11.946 & 3.353 & 15.900 & 4.218 \\
\hline
\end{tabular}

the liquid in the soil sample. Referring to (Fig. 8), the consistency of the colour showed primary porosity to be present in that particular area and the LNAPL migration occurred through the primary porosity in addition to both secondary porosity and fractured porosity. This study also used the partially unsaturated fractured double-porosity soil and the permeability test for kaolin soil proved kaolin has permeability characteristic, thus it could be expected that primary porosity could transport the LNAPL, not just the secondary and fractured porosity.

The measured values of dyed LNAPL migration depth as a function of column circumference for selected critical time intervals are shown in (Figs. 10 and 11) for samples 1 and 2, respectively. Referring to (Fig. 10), the dyed LNAPL migrated fastest between 240 to $300 \mathrm{~mm}$ and 160 to $180 \mathrm{~mm}$ along the soil column circumference because of the cracked soil surface condition compared to other locations on the soil surface that were not cracked as shown in (Fig. 7a). The dyed LNAPL migration was dramatically expedited between 5 seconds and 120 seconds, which shows the extraordinary difference in migration patterns. This could be because the factor of dyed LNAPL pressure was high at initial condition of the fractured double-porosity soil, causing the LNAPL to easily penetrate downward into the cracked soil sample.

Based on (Fig. 11), the dyed LNAPL migration was fastest between 50 to $90 \mathrm{~mm}$ and 110 to $140 \mathrm{~mm}$ along the soil column circumference. The measured actual column circumference zone as shown in (Fig. 7b) indicated the location of the surface crack. The dyed LNAPL migration was expedited between 5 - 12 seconds, which indicates significant changes in the migration pattern. This phenomena was similar to sample 1, where the influential factors were the capillary force exerted by the dyed LNAPL and high flow water pressure at the condition where the soil samples were fractured and cracked. Besides, soil sample 2 with the sufficient LNAPL head and LNAPL thickness exceeded pore entry pressure and caused the migration time to be faster compared to soil sample 1. Therefore, the aforementioned factor caused the dyed LNAPL migration to penetrate downward into the soil sample easier and faster.

The calculated higher migration flow rate and overall average speed for every $50 \mathrm{~mm}$ column circumference zone is presented in Table 1. Sample 1 shows the higher migration flow rate from initial to 5 seconds was at the $250 \mathrm{~mm}$ column circumference zone with the migration flow rate of $61.403 \mathrm{~mm} / \mathrm{s}$. Meanwhile, the other high migration flow rates occurred at $200 \mathrm{~mm}$ and $150 \mathrm{~mm}$ column circumference with the value of $18.837 \mathrm{~mm} / \mathrm{s}$ and $12.397 \mathrm{~mm} / \mathrm{s}$, respectively. Thus, the overall average dyed toluene migration flow rate for sample 1 is $4.389 \mathrm{~mm} / \mathrm{s}$. The highest average migration flow rate was at the $250 \mathrm{~mm}$ column cir- cumference zone at $9.145 \mathrm{~mm} / \mathrm{s}$. This could be because the larger fractured and cracked soil structure after the vibration was at the $250 \mathrm{~mm}$ position.

Sample 2 displays the higher migration flow rate from initial to 5 seconds at $50 \mathrm{~mm}$ column circumference zone with the migration flow rate of $76.778 \mathrm{~mm} / \mathrm{s}$. Meanwhile, the column circumference zone at $100 \mathrm{~mm}$ and $0 \mathrm{~mm}$ also has a high migration speed rate with the values of $20.551 \mathrm{~mm} / \mathrm{s}$ and $16.917 \mathrm{~mm} / \mathrm{s}$, respectively. The higher migration speed rate was due to the cracked or fractured soil sample surface (Fig. 7b) for the actual column circumference. Therefore, the overall average dyed toluene migration flow rate for sample 2 is $5.503 \mathrm{~mm} / \mathrm{s}$. This scenario occurred because the higher quantity of $23 \mathrm{~mm}$ thickness of LNAPL (head) in sample 2 caused the greatest pressure on top of the soil surface, forcing penetration to be faster than soil sample 1 with only $10 \mathrm{~mm}$ LNAPL thickness. The faster migration was caused by the greater entry pressure exerted by the LNAPL force on top of the fractured soil sample.

\section{CONCLUSIONS}

The laboratory experiment on LNAPL migration was carried out on fractured double-porosity soil with $30 \%$ moisture content. This purpose of the experiment was to investigate the vibration of soil sample and LNAPL behaviour as well as to differentiate the characteristics and flow rate in the fractured double-porosity soil in a circular soil column. The digital image processing technique using a self-development Matlab routine and Surfer Software was applied to analyse the APL and NAPL migration data obtained from captured digital images. From the results observed, both samples have been classified as ground type B, in which the soil has a very stiff soil structure and dis-amplification shaking during the vibration process. In sample 2 (57 seconds) LNAPL migrated faster from top to the bottom of soil column compared to sample 1 (300 seconds). Samples 1 and 2 both fully migrated to the bottom of the soil column. Furthermore, sample 2 average flow rate of $5.503 \mathrm{~mm} / \mathrm{s}$ was higher compared to the sample 1 flow rate of $4.389 \mathrm{~mm} / \mathrm{s}$. The LNAPL migration into the subsurface systems was allowed when the LNAPL head (thickness) drives the entry, as the non-wetting LNAPL capillary pressure overcomes the entry pressure. A similar experiment on NAPL migration in intact double-porosity soil by SA'ARI et al. (2015) found that the migration of NAPL from top to bottom take 2280 seconds. However, in our study similar migration condition for both sample took only 57 and 300 seconds, respectively, to reach bottom of soil column with the condition of fractured double-porosity soil. This shows the ease of liquid entry into the fractured double-porosity soil compared to intact double-porosity soil. The results proved that the factors that significantly influenced 
the LNAPL migration in soil samples 1 and 2 were the LNAPL head (thickness), soil sample fracture pattern, soil sample porosity, soil sample structure, liquid wettability in the soil sample and liquid capillary pressure. In conclusion, this study indicates that the soil sample acceleration response and LNAPL migration contour plots and the migration flow rate have provided preliminary information to researchers and professionals to comprehensively understand the pattern of LNAPL migration behaviour that could be used to identify the remediation method and to ensure sustainable consumption of groundwater.

\section{ACKNOWLEDGEMENTS}

This study was supported by the Research Management Centre (RMC), Universiti Teknologi Malaysia under Research University Grant - Tier 1 (PY/2016/06547) from the Ministry of Higher Education Malaysia. The authors would also like to thank their respective University, Public Service Department Malaysia, Geotechnical Laboratory, Hydraulic and Hydrology Laboratory, Engineering Seismology and Earthquake Engineering Research Group (eSEER), and Survey Unit, Faculty of Civil Engineering, Universiti Teknologi Malaysia for kind assistance lent to this research. The second author was supported through the federal training award by the Public Service Department under Prime Minister's Department, Malaysia.

\section{REFERENCES}

AGAOGLU, B., COPTY, N.K., SCHEYTT, T. \& HINKELMANN, R. (2015): Interphase mass transfer between fluids in subsurface formations: A review. - Advances in. Water Resources, 79, 162-194. doi:10.1016/j.advwatres.2015.02.009

ALAZAIZA, M.Y.D., NGIEN, S.K., BOB, M.M., KAMARUDDIN, S.A. \& ISHAK, W.M.F. (2017): Influence of macro-pores on DNAPL migration in double-porosity soil using light transmission visualization method. - Transport in Porous Media, 117, 103-123. doi:10.1007/s11242-017-0822-3

BAGHERIEH, A.R., KHALILI, N., HABIBAGAHI, G. \& GHAHRAMANI, A. (2009): Drying response and effective stress in a double porosity aggregated soil. - Engineering Geology, 105/1-2, 44-50. doi:10.1016/j.enggeo.2008.12.009

BARBARA, S., FELIX, S., TIVADAR, M.T., \& GABOR, S. (2016): Palaeofluid evolution in a fractured basalt hosted reservior in the Ulles-Ruzsa-Bordany area, southern sector of the Pannonian basin.- Geologia Croatica, 69/3, 281-293. doi:10.4154/ gc. 2016.25

CARMINATI, A., KAESTNER, A., LEHMAN, P. \& FLÜHLER, H. (2008): Unsaturated water flow across soil aggregate contacts.-Advances in Water Resources, 31/9, 1221-1232. doi: 10.1016/j.advwatres.2008.01.008

DAVIDSON, E.A. \& TRUMBORE, S.E. (1995): Gas diffusivity and production of CO2 in deep soils of the eastern amazon.- Tellus, 47, 550-565. doi: 10.3402/tellusb. v47i5.16071

EL-ZEIN, A., CARTER, J.P. \& AIREY, D.W. (2006): Three-dimensional finite elements for the analysis of soil contamination using a multiple-porosity approach.- International Journal for Numerical and Analytical Methods in Geomechanics, 30/7, 577-597. doi:10.1002/nag.491

FLORES, G., KATSUMI, T., INUI, T. \& KAMON, M. (2011): A simplified image analysis method to study LNAPLs migration in porous media.- Soil and Foundation, 51, 835-847. doi: 10.3208/sandf.51.835

FOOD AND AGRICULTURE ORGANIZATION (2005): Drought-resistant soils- optimization of soil moisture for sustainable plant production, FAO Land and Water Bulletin 11.- Food and Agriculture Organization of the United Nations, Rome

FREDLUND, D.G., HOUSTON, S.L., NGUYEN, Q. \& FREDLUND, M.D. (2010): Moisture movement through cracked clay soil profiles. - Geotechnical and Geological Engineering, 28/6, 865-888. doi:10.1007/s10706-010-9349-x

GHEZZEHEI, T.A., \& OR, D. (2003): Pore-space dynamic in a soil aggregate bed under a static external load.- Soil Science Society America Journal, 67, 12-19. doi: 10.2136/sssaj2003.1200

HARITH, N.S.H., ADNAN, A.R., SHOUSHTARI, A.S. (2017): Deaggregation of probabilistic ground motions in the Kota Kinabalu and Lahad Datu towns of Sabah, Malaysia.- In MATEC Web of Conferences, Seoul, South Korea, PP.09001, 2-11. doi:10.1051/matecconf/201713809001

HILLEL, D. (1998): Environmental soil physics. Academic Press, San Diego.

INTERNATIONAL ATOMIC ENERGY AGENCY (2008): Field eztimation of soil water content - A practical guide to methods, instrumentation and sensor technology, IAEA-TCS-30.- International Atomic Energy Agency, Vienna.
JANINA, H., SZABOLCS, B., \& JANOS, G. (2017): Cluster defined sedimentary elements of deep-water clastic depositional systems and their 3D spatial visualization using parametrization: a case study from the Pannonian-basin.- Geologia Croatica, 70/2, 73-78. doi:10.4154/gc.2017.06

KAMARUDDIN, S.A., SULAIMAN, W.N.A., RAHMAN, N.A., ZAKARIA, M.P., MUSTAFFAR, M. \& SA'ARI, R. (2011): Two-dimensional laboratory investigation of light non-aqueous phase liquid migration in subsurface environment. - In: Contemporary Environment Quality Management in Malaysia and Selected Countries, Serdang, Malaysia: Universiti Putra Malaysia Press.

KRISNANTO, S., RAHARDJO, H., FREDLUND, D.G. \& LEONG, E.C. (2014): Mapping of cracked soils and lateral water flow characteristics through a network of cracks. - Engineering Geology, 172, 12-25. doi:10.1016/j.enggeo.2014.01.002

LAKELAND, D.L., RECHENMACHER, A. \& GHANEM, R. (2014): Towards a complete model of soil liquefaction: the importance of fluid flow and grain motion.In: Proceedings of the Royal Society A - Mathematical, Physical and Engineering Sciences, London A470:20130453. doi:10.1098/rspa.2013.0453

LEWANDOWSKA, J., SZYMKIEWICZ, A., GORCZEWSKA, W. \& VAUCLIN, M. (2005): Infiltration in a double-porosity medium: Experiments and comparison with a theoretical model.- Water Resources Research, 41/2, W02022. doi:10.1029/2004WR003504

LI, X. \& ZHANG, L.M. (2009): Characterization of dual-structure pore-size distribution of soil. - Canadian Geotechnical Journal, 46, 129-141. doi: 10.1139/T08-110

LOKE, K.F., RAHMAN, N.A. \& NAZIR, R. (2017): Experimental study on unsaturated double-porosity soil phenomena under vibration effect.- Jurnal Teknologi, 79/4, 65-72. doi:10.11113/jt.v79.9976

LOKE, K.F., RAHMAN, N.A. \& RAMLI, M.Z. (2016): A laboratory study of vibration effect for deformable double-porosity soil with different moisture content.- Malaysian Journal of Civil Engineering, 28, SI/3, 207-222.

MAAS, H.G. \& HAMPEL, U. (2006): Photogrammetric techniques in civil engineering material testing and structure monitoring.- Photogrammetric Engineering \& Remote Sensing, 72/1, 39-45. doi:10.14358/PERS.72.1.39

MANRIQUE, E., MUCI, V. \& GURFINKEL, M. (2007): EOR field experiences in carbonate reservoirs in the United States.- SPE Reservoir Evaluation Engineering, 10, 667-686. doi:10.2118/100063-PA

NGIEN, S.K., CHIN, P.Q., HASAN, M., ALI, M.I., TADZA, M.Y.M. \& RAHMAN, N.A. (2016): Image analysis of non-aqueous phase liquid migration in aggregated kaolin. -ARPN Journal of Engineering and Applied Sciences, 11/10, 6393-6398.

NGIEN, S.K., RAHMAN, N.A., AHMAD, K. \& LEWIS, R.W. (2012): A review of experimental studies on double-porosity soils.-Scientific Research and Essays, 7/38, 3243-3250. doi:10.5897/SRE11.2131

NGIEN, S.K., RAHMAN, N.A., BOB, M.M., AHMAD, K., SA'ARI, R. \& LEWIS, R.W. (2011): Observation of light non-aqueous phase liquid migration in aggregated soil using image analysis.- Transport in Porous Media, 92/1, 83-100. doi:10.1007/ s11242-011-9892-9S

OOSTROM, M., DANE, J.H. \& WIETSMA, T.W. (2007): A review of multidimentional, multifluid, intermediate-scale experiments: Flow behaviour, saturation imaging and tracer detection and quantification.- Vadose Zone Journal, 570-598. doi:10.2136/vzj2006.0178

PAO, W.K.S. \& LEWIS, R.W. (2002): Three-dimensional finite element simulation of three-phase flow in a deforming fissured reservoir-- Computer Methods in Applied Mechanics and Engineering, 191/23-24, 2631-2659. doi:10.1016/S00457825(01)00420-0

PENG, Z., DUWIG, C., DELMAS, P., GAUDET, J.P., STROZZI, A.G., CHARRIER, P. \& DENIS, H. (2015): Visualization and characterization of heterogeneous water flow in double-porosity media by means of X-ray computed tomography.- Transport in Porous Media, 110, 543-564. doi:10.1007/s11242-015-0572-Z

RYZHIK, V. (2007): Spreading of a NAPL lens in a double-porosity medium.-Computational Geosciences, 11/1, 1-8. doi:10.1007/s10596-006-9040-8

SA 'ARI, R., RAHMAN, N.A., LATIF ABDUL, N.H., YUSOF, Z.M., NGIEN, S.K., KAMARUDDIN, S.A., MUSTAFFAR, M. \& HEZMI, M.A. (2015): Application of digital image processing technique in monitoring LNAPL migration in double porosity soil column.- Jurnal Teknologi, 3/72, 23-29. doi:10.11113/jt.v72.4018

SITTHIPHAT, E.A. \& SIAM, Y. (2016): Investigation of average optical density and degree of liquids saturation in sand by image analysis method.- KKU Eng. Journal, 43/S1, 147-151. doi:10.14456/kkuenj.2016.44

SOIL SCIENCE SOCIETY OF AMERICA(1987): Glossary of soil science terms.- Soil Science Society of America, Madison.

TIAN, J., WANG, J., HAO, Y., DU, H. \& LI, X. (2014): Toluene sensing properties of porous Pd-loaded flower-like $\mathrm{SnO}_{2}$ microspheres.- Sensors and Actuators, B202, 795-802. doi:10.1016/j.snb.2014.05.048

TOMLINSON, D.W., RIVETT, M.O., WEALTHALL, G.P., \& SWEENEY, R.E.H. (2017): Understanding complex LNAPL sites: Illustrated handbook of LNAPL transport and fate in the subsurface.- Journal of Environmental Management, 204, 748-756. Doi:10.1016/j/jenvman,2017.05045

TRANNGOC, T.D., LEWANDOWSKA, J. \& BERTIN, H. (2014): Experimental evidence of the double-porosity effects in geo-meterials.-Acta Geophysica, 62, 642655. doi:10.2478/s11600-013-0198-X 